\title{
Parameter Demografi Opius chromatomyiae (Hymenoptera: Braconidae) pada Lalat Pengorok Daun Liriomyza huidobrensis (Diptera: Agromyzidae)

\author{
RUSLI RUSTAM ${ }^{1}$, AUNU RAUF $^{2}$, NINA MARYANA ${ }^{2}$, PUDJANTO $^{2}$, DADANG $^{2}$ \\ ")Program Studi Hama dan Penyakit Tanaman, Jurusan Agronomi, \\ Fakultas Pertanian, Universitas Riau \\ ${ }^{2}$ Departemen Proteksi Tanaman, Fakultas Pertanian, Institut Pertanian Bogor
}

(diterima September 2008, disetujui Desember 2008)

\begin{abstract}
Demographic parameter of Opius chromatomyiae (Hymenoptera: Braconidae) on Leafminer Liriomyza huidobrensis (Diptera: Agromyzidae). Opius chromatomyiae (Hymenoptera; Braconidae) is an endoparasitoid attacking leafminers in the field. The objective of the research is to study the statistical demographic of the parasitoid. Result showed that female lifespan ( 9.95 days) was shorter than male (11.73). Female fecundity was about $104.73 \mathrm{eggs}$, with rate of egg production per day was about 9.31 eggs. This parasitoid was also found to be female-biased sex ratio. Regarding population parameter, net reproduction rate (Ro) was about 28.55 , generation time $(T)$ was 15.96 days, intrinsic rate $(r)$ was 0.21 and finite rate of increase ( $\lambda$ ) 1.23. The stable age of Opius chromatomyiae was about 37.93 $\%$ eggs, $24.92 \%$ larval, $20.36 \%$ pupae and $16.78 \%$ adult.
\end{abstract}

KEYWORDS : Opius chromatomyiae, parasitoid, net reproduction.

\section{PENDAHLUAN}

Lalat pengorok daun Liriomyza huidobrensis (Blanchard) (Diptera: Agromyzidae) telah menjadi salah satu hama penting pada pertanaman sayuran sejak kedatangannya di Indonesia sekitar awal tahun 1990-an (Rauf 1995). Lalat L. hudobrensis bersifat polifag dengan inang meliputi tumbuhan dari famili Chenopodiaceae, Compositae, Cucurbitaceae, Leguminoceae, Liliaceae, Solanaceae, Tropaeolaceae, Umbeliferae, dan Violaceae (Spencer 1973). Serangan hama ini dapat menurunkan produksi tanaman antara 30-70\% (Rauf \& Shepard 1999).

$$
\text { Umumnya petani sampai }
$$
sekarang masih mengandalan insektisida dalam pengendalian hama tersebut, namun tidak memberikan hasil yang memuaskan. Walaupun ada insektisida yang efektif, tetapi harganya sangat mahal. Penggunaan insektisida sering memberikan pengaruh samping yang buruk. Selain mematikan musuh alami, hama sasaran dapat menjadi resistensi terhadap insektisida yang digunakan (Parella 1982; Johnson 1993), sehingga pengendalian hama ini semakin sulit. 
Oleh karena itu perlu dikembangkan berbagai alternatif teknik pengendalian yang lebih ramah lingkungan.

Salah satu teknik pengendalian lalat pengorok daun adalah pemanfaatan musuh alami, diantaranya parasitoid. Penelitian yang dilakukan oleh Rauf et al. (2000) dan Tapahillah (2002), mengungkapkan bahwa salah satu parasitoid yang dominan yang ditemukan adalah Opius chromatomyiae Wharton \& Belokobylsky (Hymenoptera: Braconidae). Kajian tentang bioekologi $O$. chromatomyiae khususnya parameter demografi belum pernah dilaporkan. Informasi yang lengkap tentang bioekologi $O$. chromatomyiae sangat diperlukan agar dapat dirancang teknologi pengendalian hayati yang tepat guna pengendalian lalat pengorok daun tersebut. Laju reproduksi kotor, laju reproduksi bersih, laju pertumbuhan intrinsik, rerataan masa generasi merupakan formulasi standar untuk mengukur populasi serangga (Birch 1948; Carey 1982).

Penelitian bertujuan untuk memahami bioekologi parasitoid $O$. chromatomyiae yang mencakup statistik demografi meliputi parameter kehidupan imago, rataan masa generasi (T), laju reproduksi bersih (Ro), laju pertambahan instrisik $(\mathrm{rm})$ dan proporsi usia stabil (px).

\section{BAHAN DAN METODE}

\section{Tempat dan Waktu}

Penelitian dilakukan di Laboratorium Ekologi Serangga, Departemen Proteksi Tanaman, Institut Pertanian Bogor selama bulan November 2006 - April 2007.

\section{Penyiapan Tumbuhan Inang}

Tumbuhan inang yang digunakan untuk membiakkan $L$. huidobrensis adalah kacang jogo. Benih ditanam dalam polibag (tinggi $20 \mathrm{~cm}$, diameter $13 \mathrm{~cm}$ ) dengan menggunakan medium tanah yang dicampur pupuk kandang dengan perbandingan 3:1. Bibit tanaman disiram setiap hari agar tumbuh subur. Untuk keperluan pembiakan $L$. huidobrensis digunakan bibit yang berumur 14 hari, yaitu yang memiliki empat helai daun yang telah berkembang sempurna.

\section{Pembiakan Massal Lalat Pengorok Daun}

Lalat pengorok daun, $L$.
huidobrensis dibiakkan dalam
kurungan berkerangka kayu yang
berukuran panjang $80 \mathrm{~cm}$, lebar $40 \mathrm{~cm}$
dan tinggi $65 \mathrm{~cm}$. Alas kurungan
terbuat dari papan kayu sebagai tempat
untuk meletakkan tanaman. Bagian
samping kurungan terbuat dari kain
kasa, sedangkan bagian depan dan
belakang serta atas terbuat dari
lembaran plastik bening. Pada bagian


depan terdapat pintu untuk memasukkan tanaman dan serangga.

Kedalam kurungan pembiakan dimasukkan delapan polibag tanaman kacang jogo, dan selanjutnya dimasukkan populasi lalat pengorok daun hasil pengumpulan dari lapangan. Setelah 24 jam, tanaman yang telah diteluri oleh lalat pengorok daun dikeluarkan dan diganti dengan tanaman yang baru. Selama dalam pembiakan lalat diberi makan larutan madu $10 \%$ yang diresapkan pada kapas yang digantung dengan benang pada atap kurungan.

Tanaman yang telah diinfenstasi telur L. huidobrensis dimasukkan ke dalam kurungan pembiakan lain yang bebas serangga, dan dipelihara hingga telur menetas menjadi larva. Menjelang larva keluar dari korokan untuk berkepompong, tangkai daun dipotong dan daun kemudian disimpan dalam wadah plastik bercorong (tinggi $15 \mathrm{~cm}$, diameter $24 \mathrm{~cm}$ ). Imago $L$. huidobrensis yang muncul dan terkumpul pada corong lalu digunakan lagi untuk pembiakan. Sebagian dari tanaman yang telah terinfestasi larva pengorok digunakan untuk pembiakan parasitoid seperti diuraikan di bawah ini.

\section{Pembiakan massal parasitoid Opius chromatomyiae}

Parasitoid $O$. chromatomyiae dipelihara dalam kurungan pembiakan, dan diberi larutan madu $10 \%$ sebagai makanan. Kedalam kurungan kemudian dimasukkan sebanyak delapan polibag tanaman kacang jogo yang daunnya telah terinfestasi larva $L$. huidobrensis instar-3. Setelah 24 jam tanaman dikeluarkan dari kurungan dan diganti dengan tanaman yang baru. Larva instar-3 yang telah diparasit dimasukkan ke dalam kurungan pembiakan lain yang bebas serangga. Setelah larva membentuk pupa (sekitar tujuh hari), tanaman kacang jogo dipotong dan dimasukkan ke dalam wadah plastik. Parasitoid yang muncul digunakan untuk percobaan.

\section{Parameter Demografi Opius chromatomyiae}

Untuk menentukan sintasan pra-dewasa, ke dalam sebuah kurungan kasa yang berisikan lebih kurang 100 imago $O$. chromatomyiae dimasukkan sebanyak dua puluh tanaman (10 pot), dengan masing-masing tanaman terinfestasi oleh sekitar $20-30$ larva inang instar-3. Parasitisasi berlangsung selama 2 jam (pk. 9.00-11.00 WIB). Setiap tanaman kemudian dipindahkan ke kurungan lain dan selanjutnya dipelihara. Setiap hari perkembangan dan mortalitas pradewasa $O$. chromatomyiae diamati dengan membedah 50 korokan dan inang (larva atau pupa) di bawah mikroskop stereo.

Untuk menentukan sintasan imago dan banyaknya keturunan, sepasang imago $O$. chromatomyiae 
yang baru muncul dimasukkan ke dalam kurungan stoples yang berisi daun kacang merah dengan sekitar 2030 larva inang. Setiap 24 jam dilakukan penggantian larva inang sampai imago parasitoid mati. Jantan yang mati segera diganti dengan yang baru. Percobaan dilakukan pada 22 imago betina. Telur yang diletakkan setiap hari dipelihara dengan memelihara larva yang terparasit sampai menjadi imago.

Parameter demografi $O$. chromatomyiae diduga dengan menggabungkan data perkembangan dan sintasan pradewasa, data masa hidup imago dan reproduksi, serta data nisbah kelamin seperti yang dilakukan oleh Lysyk (2000). Usia sejak lahir hingga mati dihitung sebagai $\mathrm{x}_{\mathrm{t}}$ (masa perkembangan pradewasa + usia imago saat mati, x). Sintasan dari saat lahir hingga usia $x_{1}\left(l_{x t}\right)$ ditentukan sebagai hasil perkalian sintasan pradewasa dengan sintasan sejak imago muncul hingga berumur $x$. Parameter demografi yang dihitung adalah (Lysyk 2000):

Laju reproduksi bersih $(\mathrm{Ro})=\sum \mathrm{L}_{\mathrm{x}} \mathrm{m}_{\mathrm{x}}$

Masa generasi $(T)=\sum x \cdot L_{x} m_{x} / R_{0}$

Laju pertambahan intrinsik (r)

$$
(\mathrm{r})=\sum \mathrm{e}^{\mathrm{rx}} \cdot \mathrm{L}_{\mathrm{x}} \mathrm{m}_{\mathrm{x}}=1
$$

Laju pertambahan terbatas $(\lambda)=\mathrm{e}^{\mathrm{r}}$ Nilai reproduktif $(\mathrm{Vx} / \mathrm{Vo})=$

$$
\left(\mathrm{e}^{-\mathrm{rx}} / \mathrm{Lx}\right) \cdot\left(\Sigma \mathrm{e}^{-r y} \text { ly.my }\right)
$$

Distribusi sebaran umur (px) :

$$
100 \beta \mathrm{Lx} \mathrm{e}^{-r(x+1)}
$$

\section{HASIL DAN PEMBAHASAN}

\section{Parameter hayati Opius chromatomyiae}

Imago betina

$O$. chromatomyiae dapat dibedakan dengan imago jantan dengan ditandai adanya ovipositor pada ujung abdomen betina yang berfungsi sebagai alat meletakkan telur. Imago betina memarasit inangnya dengan cara menusukkan ovipositor tersebut ke tubuh inang dan meletakkan telurnya. $O$. chromatomyiae merupakan endoparasitoid yang memarasit larva instar akhir Liriomyza huidobrensis (Rustam 2002).

Rerata lama hidup imago jantan tidak jauh berbeda dengan imago betina dengan nilai berturut-turut $11,73 \pm 4,07$ hari dan $(9,95 \pm 2,34$ hari (Tabel 1). Imago betina yang baru muncul dari pupa dapat langsung meletakkan telurnya baik yang dikawini jantan maupun tidak.

Hal ini ditandai dengan masa praoviposisi yang 0 hari atau tanpa praoviposisi. Periode oviposisi berlangsung maksimum 14 hari dan minimum 5 hari dengan rataan $9,86 \pm 2,47$ hari (Tabel 1). 
Tabel 1. Parameter kehidupan imago Opius chromatomyiae

\begin{tabular}{lcccc}
\hline \multicolumn{1}{c}{ Parameter } & $\mathrm{N}$ & Minimun & Maksimum & Rerata $\pm \mathrm{SD}$ \\
\hline Lama hidup imago betina (hari) & 22 & 6 & 14 & $9,95 \pm 2,34$ \\
Lama hidup imago jantan (hari) & 22 & 5 & 20 & $11,73 \pm 4,07$ \\
Laju peneluran (butir/hari) & 22 & 4 & 15 & $9,31 \pm 3,41$ \\
Lama pra oviposisi (hari) & 22 & 0 & 0 & 0 \\
Lama oviposisi (hari) & 22 & 5 & 14 & $9,86 \pm 2,47$ \\
Lama pasca oviposisi & 22 & 0 & 1 & $0,09 \pm 0,29$ \\
Keperidian & 22 & 68 & 163 & $104,73 \pm 22,09$ \\
Nisbah kelamin keturunan (\%jantan) & 22 & 6,94 & 57,30 & $35,61 \pm 14,04$ \\
\hline
\end{tabular}

Ket. SD $=$ Standar deviasi

Keperidian, dalam hal ini yang diamati jumlah keturunan yang dihasilkan oleh seekor imago betina selama hidupnya berkisar 68-163 ekor, dengan rataan $104,73 \pm 22,09$ ekor. Jumlah ini jauh lebih besar diban-dingkan parasitoid lalat pengorok lain seperti Hemiptarsenus varicornis (Eulopiodae) sebesar 51,65 (Hidrayani 2003) dan Asecodes deluchii (Eulo-pidae) sebesar 11,95 (Muzuma 2004).

Nilai keperidian O. Chromatomyiae lebih tinggi dibandingkan nilai keperidian $L$. huidobrensis sebagai inangnya $(88,27)$ (Purnomo 2003). Ini mengindikasikan $O$. Chromatomyiae mempunyai potensi biologi yang besar sebagai agens pengendalian hayati lalat pengorok daun.

\section{Sintasan dan keperidian harian}

Keperidian dapat diduga dari banyaknya imago keturunan yang muncul. Berdasarkan hal demikian, peneluran $(\mathrm{mx})$ mulai terjadi pada imago yang berumur 1 hari dan mencapai puncaknya pada imago berumur 3 hari dengan rataan laju keperidian harian 9,31 (Gambar 1). Penelurun mulai menurun sejak imago berumur 3 hari. Proporsi individu yang bertahan hidup (lx) menurun tajam sejak imago berumur 6 hari dan mencapai 0 setelah hari ke-14. Kurva peluang hidup tersebut memperlihatkan pola tipe I, yakni kematian banyak terjadi pada individu-individu dewasa yang telah tua atau pada akhir perkembangan. Kurva peluang hidup tipe I umumnya ditemukan pada serangga yang dipelihara di laboratorium karena terhindar dari berbagai gangguan luar (Price 1997).

\section{Nisbah kelamin}

Nisbah kelamin dinyatakan dengan nilai persentase imago jantan terhadap jumlah parasitoid. Dari hasil penelitian yang dilakukan diperoleh 


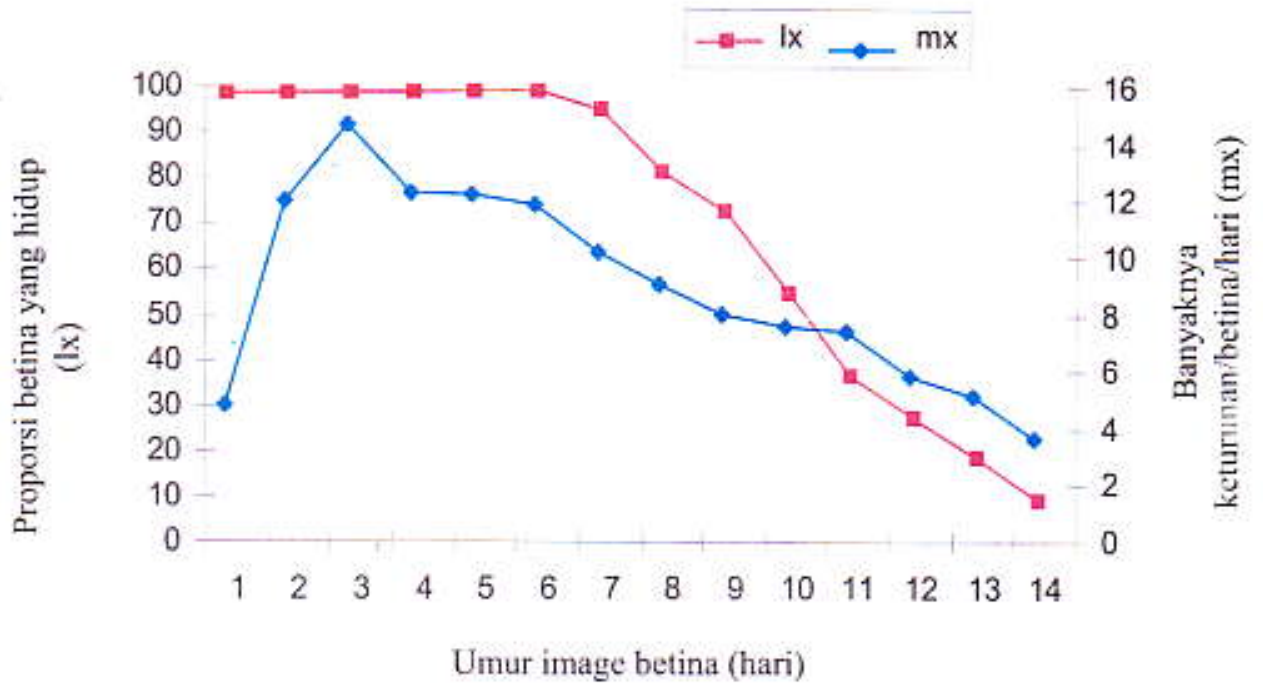

Gambar 1. Kurva sintasan imago betina Opius chromatomyiae

nisbah kelamin 0 . chromatomyiae berkisar antara 6,94-57,30\% dengan rataan 35,61 $\pm 14,04 \%$ (Tabel 1). Nisbah kelamin yang bias betina pada Hymenoptera juga dilaporkan oleh beberapa peneliti lain (Wylie 1976, Donaldson \& Walter 1984, Mazanec 1988), sebagai akibat sistim reproduksi arenotoki pada betina yang kawin (Crozier 1977). Pada pola reproduksi tadi, telur berkembang secara partenogenetik atau zigogenetik tergantung pada terjadi atau tidaknya pembuahan. Alokasi jenis kelamin pada tiap individu keturunannya dipengaruhi oleh kondisi inang (Flanders 1946). Dalam penelitian ini, diguna- kan larva instar-3 dengan jumlah yang berlimpah. Kondisi optimal yang demikian mendukung parasitoid untuk mengalokasikan lebih banyak jenis kelamin betina pada keturunannya (Charnov \& Skinner 1985).

\section{Parameter demografi}

Laju reproduksi bersih (Ro), laju pertumbuhan intrinsik (r), laju pertumbuhan terbatas $(\lambda)$, waktu satu generasi (T) nilai reproduktif $(\mathrm{Vx} / \mathrm{Vo})$, serta proporsi masing-masing kelas umur pada distribusi umur stabil (px) dihitung berdasarkan data peluang hidup (Lx) dan keperidian (mx). Hasil perhitungan tersebut disajikan pada

Tabel 2. Parameter demografi Opius chromatomyiae

\begin{tabular}{llc}
\hline & Parameter & Nilai \\
\hline Laju reproduksi bersih (Ro) & 28,55 \\
Rataan masa generasi (T) & 15,96 \\
Laju pertambahan intrinsik (r) & 0,21 \\
Laju pertambahan terbatas $(\lambda)$ & 1,23 \\
\hline
\end{tabular}


Parasitoid $O$, chromatomyiae mempunyai nilai Ro sebesar 28,55. Nilai ini memperlihatkan bahwa ratarata jumlah keturunan betina yang dihasilkan oleh seekor betina induknya adalah 28,55 betina/induk/generasi atau populasi $O$. chromatomyiae berlipat ganda $28,55 \mathrm{kali}$ dalam setiap generasi. Pada kondisi lingkungan tanpa batas, populasi $O$. chromatomyiae dapat berkembang dengan cepat karena memiliki laju reproduksi bersih $(\mathrm{Ro})>1$.

Lama waktu satu generasi (T) $O$. chromatomyiae adalah 15,96 hari. Nilai ini menunjukan bahwa dalam waktu 15,96 hari betina $O$. chromatomyiae yang muncul mampu menghasilkan separuh dari keturunannya. Nilai laju pertumbuhan intrinsik (r) O. chromatomyiae adalah 0,21 betina/induk/hari, dengan laju pertumbuhan terbatas $\lambda=\mathrm{e}^{\mathrm{r}} 1,23$ hari. Nilai ini menunjukkan besarnya kelipatan populasi $O$. chromatomyiae (ckor) per hari.

Southwood (1995) menekankan bahwa parameter $r$ adalah laju pertambahan per individu atau laju pertambahan intrinsik dimana keperidian dan sintasan maksimal, yaitu pada keadaan tidak ada faktor mortalitas eksternal. Hal ini terjadi bila populasi memiliki jadwal Ix dan $m x$ yang tetap serta kematian hanya terjadi oleh faktor fisiologis (Price 1997). Makin besar nilai $r$ makin tinggi potensi suatu spesies meningkat populasinya pada kondisi lingkungan tertentu. Selain itu, $r$ juga merupakan parameter hayati yang paling penting karena dapat digunakan untuk membandingkan potensi peningkatan di antara berbagai spesies. Dalam hubungan ini, $\mathrm{r}$ untuk parasitoid $O$. chromatomyiae $(0,21)$ lebih besar daripada $\mathrm{r}$ untuk parasitoid $H$. varicornis $(0,208)$ (Thamrin 2003). Kedua parasitoid ini memperlihatkan kehidupan yang berbeda. Parasitoid $H$. varicornis bersifat ektoparasitoid sedangkan $O$. chromatomyiae bersifat endoparasitoid, sehingga keduanya dapat saling melengkapi. Seperti halnya $H$. varicornis, parasitoid $O$. chromatomyie juga merupakan parasitoid yang potensial karena memiliki laju pertambahan intrinsik (r) yang lebih tinggi daripada $r$ hama L. huidobrensis $(0,17)$ (Supartha 1998; Purnomo 2003).

Nilai reproduktif $(\mathrm{Vx} / \mathrm{Vo})$ merupakan ukuran sumbangan relatif individu berumur $x$ terhadap populasi pada generasi berikutnya. Pada Gambar 2 ditunjukkan bahwa nilai reproduktif pada awalnya terlihat meningkat terus hingga mencapai puncaknya, kemudian menurun dengan bertambahnya umur. Nakamura et al. (1984) menyebutkan bahwa nilai reproduktif suatu individu biasanya meningkat sampai awal masa reproduksi, kemudian akan menurun dengan bertambahnya umur. Nilai reproduktif $O$. chromatomyiae 


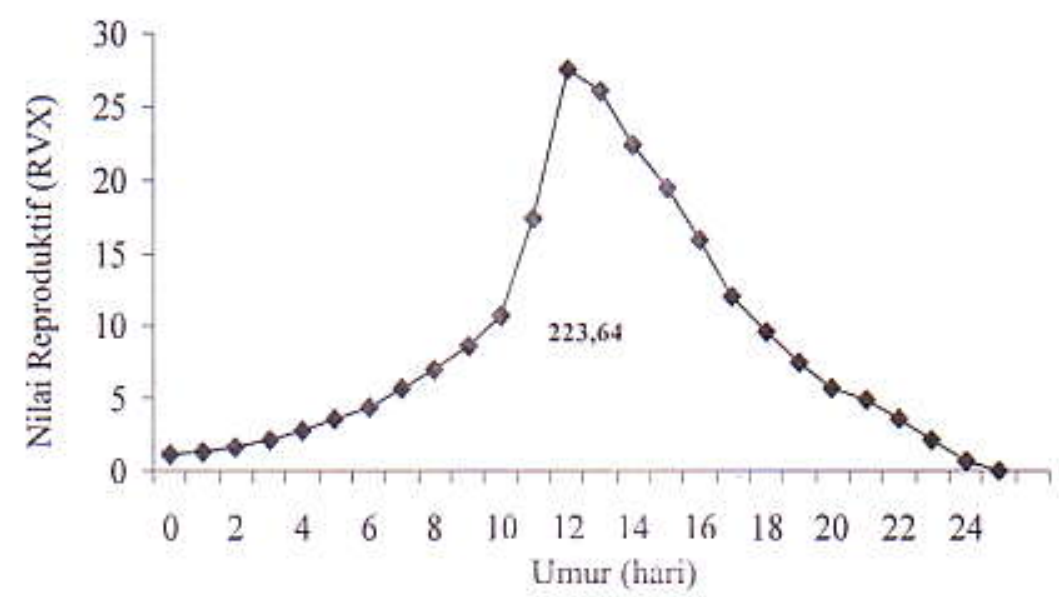

Gambar 2. Nilai reproduksi $O$. chromatomyiae menurut umur

tertinggi dimiliki oleh individu yang berumur 12 hari atau imago berumur 3 hari. Area di bawah kurva memperlihatkan jumlah total nilai reproduktif untuk semua umur, yang nilainya adalah 223,64 .

Persebaran umur stabil $O$. chromatomyiae, adalah $37,93 \%$ telur, $24,92 \%$ larva, $20,36 \%$ pupa dan $16,78 \%$ imago (Tabel 3). Kondisi persebaran umur stabil ini merupakan prasyarat bagi tercapainya laju pertambahan instrisik $(r=0,21)$.

Melalui simulasi menggunakan model matriks Lelslie dapat diperkirakan kapan terjadinya persebaran umur stabil pada populasi
O. chromatomyiae. Simulasi dengan melepaskan imago betina $O$. chromatomyiae yang siap kawin sebanyak 100 individu dan simulasi dijalankan untuk 100 hari. Hasil simulasi menunjukkan keragaman persebaran umur stabil dari hari ke hari (Gambar 3). Namun keragaman tersebut akhirnya menurun dan hampir mencapai persebaran umur stabil pada hari ke 100. Untuk mencapai nilai stabil yang aktual maka simulasi ini dilanjutkan dengan 125 hari. Konvergensi ke arah sebaran umur stabil merupakan ciri dari matriks Leslie, berapapun banyaknya parasitoid yang dilepaskan.

Tabel 3. Proporsi berbagai fase perkembangan O. chromatomyiae pada persebaranumur stabil

\begin{tabular}{cc}
\hline Fase perkembangan & Proporsi (\%) \\
Telur & 37,93 \\
Larva & 24,92 \\
Pupa & 20,36 \\
Imago & 16,78 \\
\hline
\end{tabular}




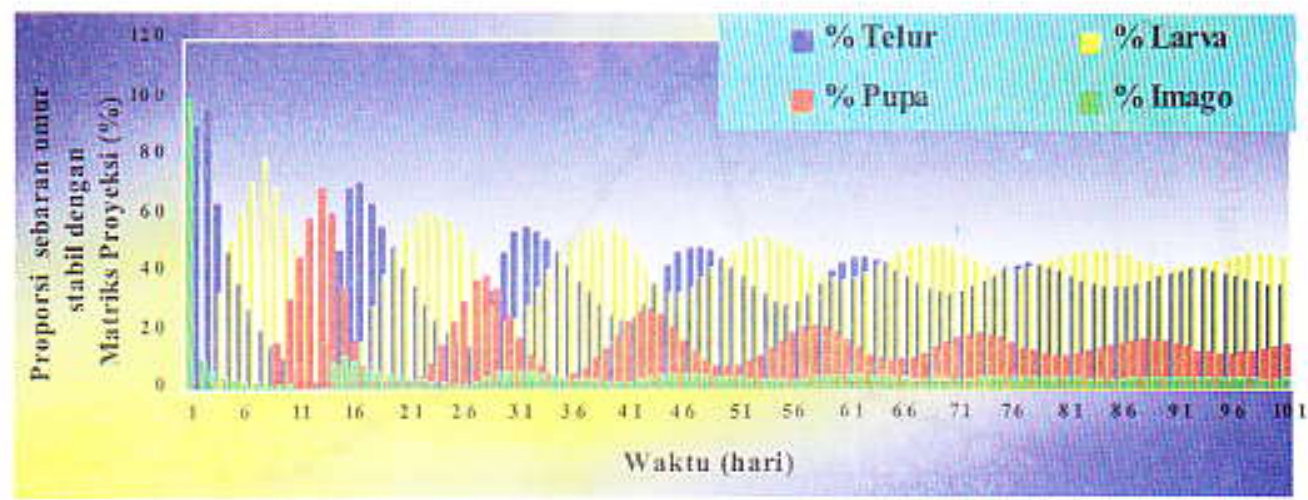

Gambar 3. Perubahan proporsi fase perkembangan parasitoid $O$. Chromatomyiae

\section{Simpulan}

\section{Endoparasitoid}

Opizs

chromatomyiae sangat berpotensi dalam mengendalikan lalat pengorok daun di lapangan. Dengan kemampuan reproduksi yang tinggi (104,73 butir) dan lama hidup imago yang cukup panjang $(9,95$ hari) akan mampu mengendalikan populasi lalat pengorok daun sebagai serangga inangnya di lapangan, sedangkan laju reproduksi bersih (Ro) 28,55 dengan masa generasi (T) 15,96 hari dan laju pertumbuhan intrinsik sebesar 0,21 . O. chromatomyiae. Proporsi usia stabil yang didominasi oleh serangga pradewasa mendukung sekali dalam pemanfaatan parasitoid ini sebagai endoparasitoid dalam pengendalian lalat pengorok daun.

\section{DAFTAR PUSTAKA}

Birch LC. 1948. The intrinsie rate of natural increase of an insect population, $p$ : 79-90. In: Hazen WE (ed). Reading in Population and Community:
Ecology, Second Ed. W.B. Saunders Co. Philadelphia.

Carcy JR. 1982. Practical applicatian of the stable age distribution: analysis of a Tetranychid mite (Acari: Tetranychidae) population outbreak. Environ Entomol 12:10-18.

Charnoy EL, Skinner SW. 1985. Complementary approaches to understanding of parasitoid oviposition decition. Enviromen Entomol 14:383-391.

Clausen RF, 1940. Entomophagous insect. New York and London: Mc GrawHill Book Company, Inc.

Crozier RH. 1977. Evolutionary genetic of Hymenoptera. Annu Rev Entomol 22 $: 263: 288$.

Donaldson IS, Walter GH. 1984. Sex ratio of Spalangia endulis (Hymenoptera: Pteromalidac) in relation to current theory. Econ Entomol 9: 395-402.

Flanders SE, 1946. Control of sex and sexlimited polymorphism in the Hymenoptera. Quart Rev Biol 21:135-143.

Hidrayani. 2003, Bioekologi Hemiptarsenus varicornis ( Girault) (Hymenoptera: Eulopidae), parasitoid Liriomyza huidobrensis (Blanchard) (Dipetara: Agromyzidae) (Diptera: Agro- 
myzidae) [Disertasi]. Bogor: Program Pascasarjana, Institut Pertanian Bogor.

Johnson MW. 1993. Biological control of Liriomyza leafminers in the Pasific Basin. Micronesia 4: 81-92.

Lysyk TJ, 2000. Relationship between temperature and life history parameters of Muscidifirax raptor (Hymenoptera: Pteromalidae). Environ Entomol 29(3): 596-605.

Mazanec Z. 1988. Immature stage and life history of Chrysonotomyia sp. C. (Hymenoptera: Eulopidae), a parasit of the jarrah leafminer. $J$ Aust Entomol Aus 27:279-292.

Muzuma 2004. Biologi parasitoid Asecodes deluchii (Boucek) (Hymenoptera: Eulopidae) pada larva Liriomyza sativae Blanchard (Diptera : Agromyzidae), dan tingkat parasitisasinya di pertanaman oyong [tesis]. Bogor: Program Pascasarjana Institut Pertanian Bogor.

Nakamura K. et al. 1984. Survivorship and fertility schedules of two Epilachnine "spesies" feeding on cucurbitaceous plant under laboratory conditions (Coleoptera: Coccinellidae). Appl Ent Zool 19(1):59-66.

Parella MP. 1982. A view of the history and taxonomy of economically important serpentine leafminers (Liriomyza spp.) in California (Diptera:Agromyzidae). Pan Pac Entomol 58 (4):302-308.

Price PW. 1997. Insect ecology. Third edition. New York, Chichester, Weinhein, Brisbane, Singapore, Toronto: Jhon Wiley \& Sons.

Purnomo. 2003. Liriomyza huidobrensis (Blanchard) (Diptera; Agromyzidae): Kesesuaian inang, perkembangan populasi, dan pengaruh insektisida translamina [Disertasi]. Bogor;
Program Pascasarjana, Institut Pertanian Bogor.

Rauf A. 1995. Liriomyza: hama pendatang baru di Indonesia. Bul HPT 8 (1): 4648.

Rauf A \& Shepard BM. 1999. Leafminers in vegetables in Indonesia: surveys of host crops. Species composition. parasitoids and control practices. In: Worhshop of Leafminers of Vegetables in Southeast Asia; Selangor, 2-5 February 1999. Selangor: CAB International, Southeast Asia Regional Center.

Rauf A, Shepard BM, \& Johnson MW. 2000. Leafminers in vegetables, ornamental plants and weeds in Indonesia: surveys of host crops, species compositio and parasitoids. Intern J Pest Manage 46 (4): 257 - 266.

Rustam R. 2002. Biologi Opius sp.(Hymenoptera: Braconidae) parasitoid lalat pengorok daun kentang [Tesis]. Bogor: Program Pascasarjana, Institut Pertanian Bogor.

Southwood TRF. 1995. Ecological methods, 2nd ed. London: Chapman \& Hall. $524 \mathrm{p}$.

Spencer KA. 1973. Agromyzidae (Diptera) of economic importance. Dr W Junk BV. The Haque.

Supartha IW. 1998. Bionomi lalat pengorok daun, Liriomyza huidobrensis (Blanchard) (Diptera: Agromyzidae), pada pertanaman kentang [Disertasi]. Bogor: Program Pascasarjana, Institut Pertanian Bogor.

Tapahillah T. 2002. Survei lalat pengorok daun Liriomyza spp. (Diptera: Agromyzidae) dan parasitoidnya pada berbagai tumbuhan inang dan ketinggian tempat di Jawa Barat (Diptera: Agromyzidae) [Skripsi]. Bogor: Institut Pertanian Bogor. 
Thamrin S. 2003. Potensi Parasitoid Hemiptarsemus varicornis (Girault) (Hymenoptera: Eulophidae): Paralisis, Pemangsaan Inang dan Laju Pertumbuhan Instrinsik [tesis]. Bogor: Program Pascasarjana, Institut Pertanian Bogor.
Wylie HG. 1976. Observation on the life history and sex ratio variability of Eupteromalus dubilalis (Hymenoptera: Pteromalidae), a parasit of cyclorrhaphous dipetera. Can Enromol 108:1267-1274. 